Wilfrid Laurier University

Scholars Commons @ Laurier

2016

\title{
Age-Related Differences in Moral Identity Across Adulthood
}

Tobias Krettenauer

Wilfrid Laurier University, tkrettenauer@wlu.ca

Andrea Lourdes Murua

Fanli Jia

Follow this and additional works at: https://scholars.wlu.ca/bpsy_faculty

Part of the Developmental Psychology Commons

\section{Recommended Citation}

Krettenauer, T., Murua, L. \& Jia, F. (2016). Age-related differences in moral identity across adulthood. Developmental Psychology, 52(6), 972-984. http://dx.doi.org/10.1037/dev0000127

This Article is brought to you for free and open access by the Psychology at Scholars Commons @ Laurier. It has been accepted for inclusion in Psychology Faculty Publications by an authorized administrator of Scholars Commons@ @aurier. For more information, please contact scholarscommons@wlu.ca. 
Running head: MORAL IDENTITY ACROSS ADULTHOOD

Age-Related Differences in Moral Identity Across Adulthood

Tobias Krettenauer, Lourdes Andrea Murua \& Fanli Jia

Wilfrid Laurier University

Krettenauer, T., Murua, L. \& Jia, F. (2016). Age-related differences in moral identity across adulthood. Developmental Psychology, 52(6), 972-984.

http://dx.doi.org/10.1037/dev0000127

Author Note

Tobias Krettenauer, Lourdes Andrea Murua, and Fanli Jia, Department of

Psychology, Wilfrid Laurier University, Waterloo, Canada.

The research presented in this paper was supported by an Insight Grant of the

Social Sciences and Humanities Research Council Canada to the first author (\#435-2012-

1070).

Please address correspondence concerning this article to: Tobias Krettenauer, Department of Psychology, Wilfrid Laurier University, 75 University Ave W, Waterloo, Ontario, N2L 3C5, Canada; email: tkrettenauer@wlu.ca. 


\begin{abstract}
In this study, age-related differences in adults' moral identity were investigated. Moral identity was conceptualized a context-dependent self-structure that becomes differentiated and (re)integrated in the course of development and that involves a broad range of value-orientations. Based on a cross-sectional sample of 252 participants aged 14 to 65 years (148 women, $M=33.5$ years, $S D=16.9)$ and a modification of the Good Self Assessment, it was demonstrated that mean-level of moral identity (averaged across the contexts of family, school/work and community) significantly increased in the adult years, whereas cross-context differentiation showed a non-linear trend peaking at the age of 25 years. Value-orientations that define individuals' moral identity shifted so that selfdirection and rule-conformity became more important with age. Age-related differences in moral identity were associated with, but not fully attributable to changes in personality traits. Overall, findings suggest that moral identity development is a life-long process that starts in adolescence but expands well into middle age.
\end{abstract}

Key words: Moral identity, moral development, personality, adulthood 


\section{Age-related differences in moral identity across adulthood}

For more than 25 years, the moral identity construct has been discussed as a major personality characteristic and an important dimension of individual development (for overviews see Hardy \& Carlo, 2011a; Walker, 2014). Individuals differ with regard to the extent they integrate moral values into their sense of self. Some people feel that being honest, compassionate, fair or generous is central for their identity, whereas others consider non-moral values such as being active or outgoing as more important. These individual differences are attributable to different developmental trajectories, where some individuals were able to achieve a higher level of morality-self integration than others. Many researchers consider the age period of adolescence and emerging adulthood as crucial for moral identity formation (cf. Blasi, 2005; Damon \& Hart, 1988; Frimer \& Walker, 2009; Hardy \& Carlo, 2011b). Even though direct empirical evidence supporting this view is scarce (for an extensive discussion see Krettenauer \& Hertz, 2015), research provides indirect support for it. Studies following domain theory (cf. Smetana, Jambon, \& Ball, 2014) indicate that in multifaceted situations of social exclusion older adolescents more often than younger teenagers use moral reasoning rather than conventional reasoning (Brenick \& Killen, 2014; Horn, 2003). Moreover, studies on the development of moral emotions suggest an increase in adolescents' internal moral motivation that likely reflects growth in moral identity concerns (Krettenauer, Asendorpf, \& NunnerWinkler, 2013; Krettenauer, Colasante, Buchmann, \& Malti, 2014).

While moral identity research has been focusing on adolescence and emerging adulthood as a critical developmental period, this by no means implies that moral identity development is limited to this age period (Lapsley \& Stey, 2014; Damon, 1996). In a 
series of studies, Kochanska and colleagues provided important insights into the development of preschoolers' moral self as a precursor of adolescents' moral identity (Kochanska, Koenig, Barry, Sanghang, \& Yoon, 2010; Kochanska, 2002). Krettenauer, Campbell, and Hertz (2013) investigated the development of the moral self in middle childhood and provided evidence that children's moral self-concept becomes increasingly predictive of moral emotions and social behavior between the ages of 5 and 12 years (see also Sengsavang \& Krettenauer, 2015).

The importance of morality to individuals' sense of self and identity undergoes systematic development and becomes increasingly coordinated with other aspects of moral functioning, notably moral emotions and moral action. This has been investigated numerous times in childhood, adolescence and emerging adulthood. However, it has never been studied systematically in the context of adult development. As a consequence, it is largely unknown how moral identity develops beyond adolescence and emerging adulthood, whether age-related trends continue in the adult years, come to a halt, or are reversed, and how moral identity relates to other important dimensions of the adult personality. These questions define the focus of the present study. By addressing these questions we aim at charting age-related differences in moral identity across adulthood, which has been a largely unexplored area of research up to date. However, taking a life span perspective on the moral identity construct involves more than just broadening the age range of previous studies. It requires expansions in the conceptualization and measurement of the moral identity construct itself.

In the following, we will first discuss what age-related differences in adults' moral identity can be theoretically expected following research on personality development in 
adulthood. For this discussion, we adopt the integrative framework for studying personality development proposed by McAdams (2015; McAdams \& Olson; 2010). Thus, we assume that moral identity constitutes an important aspect of a person's moral personality and cannot be reduced to personality traits. In the second step, we will discuss expansions in the conceptualization and measurement of the moral identity construct that are necessitated when investigating the purported age-related differences. Following these discussions, specific hypotheses are formulated.

\section{Age-related differences in moral identity across adulthood: Theoretical expectations}

Personalities systematically change over the life span. This was documented and corroborated repeatedly in multiple longitudinal studies (Roberts, Wood, \& Caspi, 2008; Roberts, Walton, \& Viechtbauer, 2006: Lucas \& Donnellan, 2011). As individuals grow older, the personality traits of conscientiousness, agreeableness and emotional stability become stronger. By contrast, openness to experience and extraversion evidence smaller and less consistent age-trends across the life span (Bleidorn et al., 2013). The greatest mean-level changes in conscientiousness, agreeableness and emotional stability occur between the age of 20 and 45 years, when investing in new roles (e.g., as a partner, parent, collaborator or supervisor) requires people to become more considerate, selfcontrolled, responsible and emotionally stable (Roberts, Wood, \& Smith, 2005). In an attempt to characterize these developments, Roberts and Wood (2006) formulated the maturity principle of personality development, which states that personality development tends towards maturity. Following Roberts and Wood (2006), mature people are well liked, respected and sometimes even admired in their communities. As morality is 
essential for evaluating others (Goodwin, Piazza, \& Rozin, 2014), the maturity principle inevitably invokes moral qualities. Correspondingly, conscientiousness, agreeableness and emotional stability were found to define important characteristics of people who lead an exemplary moral life (Lapsley \& Hill, 2009). Low scores on these traits tend to be associated with antisocial conduct and criminal behavior (Miller \& Lynam, 2001).

As individuals grow older and mature, traits that define a moral personality become more important. However, the moral personality is not only defined by traits but involves life-goals and value-orientations as well as narratives that all contribute to a person's moral identity (Krettenauer \& Hertz, 2015; McAdams, 2009; Walker, 2014). Theoretically, there is no reason to restrict the maturity principle to traits and exclude other lines of personality development from it, notably moral identity. Therefore, agerelated increases in moral identity across adulthood as part of a more general developmental trend towards maturity can be reasonably expected.

However, development of personality traits is not limited to mean-level changes. It is also manifest in increased consistency. In longitudinal studies, rank-order stabilities of personality traits tend to increase over the life span reaching a plateau between the ages of 50 to 70 years (Roberts \& DelVecchio, 2000). At the same time, self-concept differentiation decreases in the adult years (Diehl, Hastings, \& Stanton, 2001; Diehl \& Hay, 2007, 2011; Donahue, Robins, Roberts, \& John, 1993). Thus, with age, individuals' self-descriptions tend to depend less on whether they see themselves in the context of their family, as a romantic partner, friend, or coworker. This trend is part of a more general developmental dynamic of differentiation and integration of individuals' selfrepresentations (cf. Harter, 2012). Harter and colleagues found an increased 
differentiation in self-descriptions across contexts (family, friends, school) between early and middle adolescence that was accompanied by an heightened awareness of conflict (Harter, Bresnick, Bouchey, \& Whitesell, 1997; Harter \& Monsour, 1992). This increased differentiation was followed by an integration of conflicting self-descriptions in late adolescence. A similar dynamic of self-concept differentiation and integration was documented by Elbogen, Carlo, and Spaulding (2001) in a sample of 1st and 4th year university students. Since morality is not limited to a particular social context but extends across all areas of life, it can be reasonably expected that cross-context differentiation is an important aspect of moral identity development in addition to mean-level change.

In sum, following research on personality development in adulthood, two analytically distinct age-related trends in adult moral identity development can be expected. First, the self-importance of moral values should increase with age. Second, cross-context differentiation should evidence a curve-linear trend peaking between adolescence and young adulthood.

\section{Conceptualization and Measurement of the Moral Identity Construct}

Conceptually, previous research on moral identity has been mostly based either on trait or on socio-cognitive theories (Lapsley \& Hill, 2009; Walker, 2014). Trait-based approaches assume cross-context consistency in behavior dispositions relevant to individuals' moral conduct. Socio-cognitive approaches, by contrast, stress the malleability of situation-specific knowledge structures and schemas that guide selfregulation and action. Given these theoretical foci, neither trait-based nor socio-cognitive approaches consider cross-context differentiation and integration as an important aspect of moral identity development. This limitation needs to be overcome when investigating 
age-related differences in moral identity across adulthood. Thus, moral identity needs to be conceptualized as a flexible and context-dependent self-structure that nonetheless evidences some consistency across situations. This perspective is not entailed in trait or socio-cognitive approaches to moral identity as these approaches either assume crosscontext consistency or cross-context specificity but not both. This sets any investigation of cross-context differentiation and integration of moral identity apart from trait and socio-cognitive approaches. However, the two approaches are not incompatible with the perspective taken in the present study. Lapsley and Narvaez (2004) suggested that moral identity as a trait is tantamount to chronic accessibility of moral schemas across a broad range of situations. Accessibility of moral schemas can systematically vary across social contexts depending on the demand characteristics that predominate in a particular area of life (e.g. family, workplace). As a consequence, moral identity may evidence context specificity. At the same time, individuals encounter similar moral demands across a range of situations (e.g. being honest, fair, dependable to family members and coworkers), which provides a foundation for cross-context consistency of moral identity.

To investigate the relationship between age and cross-context differentiation, moral identity needs to be assessed in a context-sensitive way. In the present study, procedures commonly used in self-concept research (see Baird, Le, \& Lucas, 2006; Donahue et al., 1993; Harter et al., 1997) were applied for assessing cross-context differentiation in individuals' moral identity. Participants were asked to rate the selfimportance of moral values independently in three different social contexts (family, school or school and community/society). The variability of ratings across contexts was then used as an indicator of cross-context differentiation of individuals' moral identity. 
A second limitation of moral identity research that needs to be overcome when investigating moral identity from a life span perspective relates to the definition of the moral domain. Standard measures of moral identity, such as the Self-Importance of Moral Identity Questionnaire (Aquino \& Reed, 2002) use a small predefined set of values that mostly focus on benevolence and dependability (e.g., being caring, friendly, generous, helpful, kind). However, as Lapsley and Hill (2009) noted, moral identity is a dimension of individual differences in a double sense. People differ on how central moral values are to their sense of self. At the same time, there are different ways of living a moral life well (Flanagan, 1991). Some individuals may orient their moral identity towards kindness and others towards fairness or integrity and these various orientations may change with age.

In a sample drawn from 12 European nations with more than 6000 adult participants, it was demonstrated that conservative values (conformity and tradition) were positively correlated with age (Robinson, 2013). The same was true for self-transcendent values (universalism, benevolence). By contrast, stimulation and self-enhancement values (achievement, hedonism) evidenced an inverse relation with age. On a more fine-grained level of analysis, differentiating between 19 value domains, Schwartz et al. (2012) reported a positive correlation between age and benevolence-dependability (being dependable, trustworthy, reliable). Similarly, an orientation towards conformity and preserving tradition was positively correlated with age, whereas tolerance (listening, understanding) was more important for younger people (see also Schwartz, 2006). Thus, value-orientations are not constant across the life span. To some extent these changes may reflect development of personality traits as agreeableness tends to be positively 
correlated with benevolence values and conscientiousness with conformity (Roccas, Sagiv, Schwartz, \& Knafo, 2002).

The value surveys used in studies by Schwartz and colleagues capture a broad range of values that do not all equally qualify as moral. This becomes evident when considering studies that investigate individuals' prototypical conceptions of a highly moral person (Hardy, Walker, Olsen, Skalski, \& Basinger, 2011; Lapsley \& Lasky, 2001; Walker \& Pitts, 1998). The value-attributes people use to characterize a highly moral person typically belong to the domains of benevolence, universalism, conformity, achievement and self-direction in Schwartz' circumplex model (Vauclair, Wilson, \& Fischer, 2014). In contrast, values that reflect an orientation towards stimulation, hedonism, power and security are typically not mentioned when describing a highly moral person. Thus, although people's prototypical conceptions of a highly moral person do not include the full range of human values, this range is much broader than the set of values that is included in standard measures of moral identity. This conclusion is supported by Moral Foundations Theory (Graham et al., 2013), which points out that the moral domain goes beyond the two moral foundations of harm and fairness (which correspond to benevolence and universalism in Schwartz' model (cf. Graham et al., 2011) but includes at least three more foundations relating to ingroup loyality, authority and purity. Lay people's definitions of the moral domain vary within and between cultures, which is not adequately reflected by standard measures of moral identity. While benevolence and universalism constitute core moral values, people sometimes include value-attributes in their conception of a highly moral person that have been characterized 
as social-conventional from the perspective of domain theory (cf. Smetana, Jambon \& Ball, 2014).

In the present study, we do not adopt a specific conceptual definition of the moral domain but consider it an empirical question what values individuals chose to define their moral identity. These values are likely multi-faceted and change with age. Therefore, in the present study, the standard procedure for assessing individuals' moral identity was modified. Participants were not presented with a predefined set of value-attributes (such as being kind, generous, fair). Rather, individuals were asked to choose those valueattributes from a longer list to define their own moral identity. These value-attributes were then classified into value domains using Schwartz' circumplex model as an analytical tool in order to investigate whether the value-orientations that define individuals' moral identity differ with age.

\section{Research Questions and Hypotheses}

In the previous sections we discussed general expectations regarding age-related differences in moral identity across adulthood along with modifications in conceptualization and measurement that are required when approaching the moral identity construct from a life span perspective. Summarizing this discussion, age-related differences in moral identity with regard to the following three aspects were expected: (1) the overall self-importance of moral values, (2) cross-context differentiation of moral identity and (3) the value-orientations that define individuals' moral identity.

(1) Based on the well documented finding that the personality traits of conscientiousness, agreeableness and emotional stability evidence significant increases between adolescence and middle age (65 years), it was expected that the overall self- 
importance of moral values (that is the mean-level of moral identity averaged across social contexts) increases between the age of 14 and 65 years. In the meta-analysis by Roberts et al (2006), personality traits of conscientiousness, agreeableness and emotional stability continuously increased from adolescence to adulthood, even though changes in these traits were most pronounced in young adulthood. Thus, change evidenced linear as well as non-linear components. If moral identity development follows age-related changes in personality traits, mean-level of moral identity may similarly evidence linear as well as non-linear trends. Therefore, linear and cubic relationships between age and mean-level of moral identity were investigated.

(2) Following studies on the development of self-concept that document increases in self-concept differentiation in adolescence and emerging adulthood followed by decreases at later developmental periods, it was expected that cross-context differentiation in moral identities increases during adolescence and emerging adulthood and decreases in the adult years. As a consequence, age should evidence a quadratic trend as a predictor of cross-context differentiation of individuals' moral identity.

(3) It has been repeatedly demonstrated that an orientation towards conformity is positively correlated with age (cf. Schwartz, 2006; Robinson, 2013). In the present study, it was therefore expected that conformity values are more important for older individuals when defining their moral identity. Other value domains that likely form a significant part of individuals' moral identity are benevolence and universalism. These domains tend to be positively correlated with age, as well. Consequently, we expected that universalism and benevolence become more important with age for individuals when defining their moral identity. However, as Schwartz et al. (2012) pointed out, the value domain of 
universalism can be further divided into universalism-concern, universalism-tolerance and universalism-nature. These subdomains tend to be differentially related to age. Whereas universalism-concern and universalism-nature evidence a positive correlation with age, a negative correlation was found for universalism-tolerance (Schwartz et al. 2012). We therefore expected that tolerance was more important for younger individuals when defining their moral identity.

Conformity, universalism and benevolence are value domains that likely represent core aspects of individuals' moral identity. However, a person's moral identity is not limited to these domains but may include others (notably achievement and self-direction). The value domain of achievement was found to be negatively correlated with age (Schwartz, 2006; Robinson, 2013). Correspondingly, we expected that achievement becomes less important as an aspect of a person's moral identity with age. Findings for the relationship between self-direction and age have been less strong and less consistent in comparison to all other value domains. Robinson (2013) reported a negative correlation of $r=-.05$ with age. Schwartz et al. (2012) found a slight negative correlation that was significant in only 15 out of 20 European countries. Because of this inconclusive evidence we did not hypothesize a specific age trend but considered it an open empirical question how the importance of self-direction as part of individuals' moral identity is related to age.

In addition to investigating age-related differences in mean-level of moral identity, cross-context differentiation as well as value-orientations, we intended to examine the degree of overlap between these differences and personality trait development. As Hill and Roberts (2010) argued, models of personality and identity 
should be considered "fellow travelers" (p. 381) for the study of moral personality development. Moreover, Wood and Roberts (2006) demonstrated that context-specific role identities contribute to changes in personality traits. Correspondingly, age-related increases in moral identity may contribute to changes in conscientiousness, agreeableness, or emotional stability over time. Conversely, age-related changes in moral identity may depend on personality trait development. Although a detailed analysis of these cross-lagged relationships is beyond the scope of the present paper, we will examine how age-related differences in moral identity relate to personality traits. In line with the framework for personality research proposed by McAdams (2015), it was expected that age-related differences in moral identity partly overlap with age-related differences in personality traits but are not fully accounted for by these variables. In order to capture the full range of personality trait development, in the present study all traits that are empirically related to age will be included. Thus, the analysis will not be a priori restricted to agreeableness, conscientiousness and emotional stability.

\section{Methods}

\section{Sample}

The sample of the present study consisted of 252 individuals (148 women) sampled from four different age groups: adolescence (14-18 years), emerging adulthood (19-25 years), young adulthood (26-45 years) and middle age (46-65 years). Sample mean was 33.48 years, $S D=16.98$. Participants' gender was unrelated to age-group, $\chi^{2}=$ $2.54, d f=3, p=.45$ (for breakdowns of demographic variables by age-group see Table $1)$. 
Participants were recruited through advertisements in local newspapers $(69.3 \%$ of participants), online postings of the study (24.7\%) and flyers distributed at community events (6\%). All participants provided informed consent before participating and received \$50 compensation. After study completion, participants were encouraged to forward the recruitment information they had initially received (newspaper ad, online link, flyer) to other potential participants.

At time of data collection, all participants were residing in South-West Ontario, which has a culturally diverse population of varying ethnic backgrounds. Of participants 75.5\% were born in Canada, whereas $24.5 \%$ had immigrated to Canada from countries located in Africa, Asia, Australia, Europe and South-America. On average, participants who were born outside Canada had been living in the country for 15.94 years, $S D=$ 12.64. Country of origin (born in Canada, $1=y e s$ vs. $0=n o$ ) was unrelated to age-group, $\chi^{2}=5.98, d f=3, p=.11($ see Table 1$)$

Most participants (76.1\%) self-identified themselves as Canadian of European descent. Of participants, 14.9\% had an Asian or East-Asian background and described themselves as Indian, Pakistani, Chinese or Vietnamese, 9\% self-identified as Arabian or Arabic. Ethnic background (European-Canadian, $1=$ yes vs. $0=n o$ ) was unrelated to agegroup in the present sample, $\chi^{2}=5.93, d f=3, p=.11$ (see Table 1).

Of participants, $40.8 \%$ were enrolled in a secondary or post-secondary educational institution at the time of the data collection (high-school, college or university). Of those participants who were not enrolled in an educational institution $(n=150), 21.7 \%$ had completed high school, $47.1 \%$ had obtained a college diploma or undergraduate degree, and $30.3 \%$ had completed graduate or professional training. Educational attainment was 
scored on a 7-point scale from $1=$ some high school to 7 = graduate or professional degree, with $4=$ completed college diploma as the midpoint of the scale (see Statistics Canada, 2011). Educational attainment as represented by this scale was unrelated to agegroup in the present sample, $F(2,147)=0.194, p=.82$ (see Table 1) and not correlated with age, $r=.02, p=.85$.

In order to assess individuals' socio-economic status (SES), participants were asked to provide descriptions of their current occupation (most recent occupation, if unemployed or retired). Participants who were enrolled in an educational institution were asked to provide descriptions of their mother's and father's occupations. Job descriptions were coded according to the International Standard Classification of Occupations (ISCO88) and transferred into the International Socio-Economic Index of Occupational Status (ISEI), which is a well-validated measure of SES (Ganzeboom, De Graaf, \& Treiman, 1992). For students, parents' ISEI scores were averaged. Theoretically, ISEI scores range from 10 to 90 with a midpoint of the scale at 50. In the present sample, participants' ISEI score was $M=50.46, S D=14.69$. Thus, sample SES was average. More importantly, the four age-groups did not differ with regard to SES, $F(3,219)=0.29, p=0.83$ (see Table 1), nor was there a significant correlation between participants' age (in years) and SES, $r$ $=.085, p=.21$.

\section{Measures}

The study consisted of a 90-minute interview and a questionnaire that took about 30 minutes to complete. The interview was conducted to assess individuals' moral identity in three different social contexts (family, school or work, community/society). The questionnaire was used to assess personality traits and social desirability response 
bias. The interview was audio-recorded and transcribed verbatim. In the interview, openended and standardized response formats were used. In the context of the present study, only standardized responses were analyzed. Thus, coding of open-ended responses was not required.

Moral Identity. The interview procedure for assessing individuals' moral identity was based on a modified version of the Good Self-Assessment (Arnold, 1993), which has been validated in several independent studies (Barriga, Morrison, Liau, \& Gibbs, 2001; Johnston \& Krettenauer, 2011; Nunner-Winkler, Meyer-Nikele, \& Wohlrab, 2007). Modifications pertained to (a) the value-attributes individuals used to define their moral identity, and (b) the context-specific assessment of moral identity. Whereas the Good Self-Assessment uses a standard list of eight moral value-attributes to assess a person's moral identity (fair, truthful, kind, respectful, loyal, compassionate, sincere, generous), in the present study, participants were asked to define their own moral identity by choosing from a longer list of 80 value-attributes. These value-attributes were then used to assess the self-importance of morality separately in three different social contexts: family, work or school (depending on participants' age and employment status), and community/society. The interview procedure for assessing individuals' moral identity as used in the present study was extensively piloted by running pilot interview with 20 participants from all age- and gender-groups involved in the main study.

The list of 80 value-attributes that was used for asking participants to define their own personal moral identity was derived from studies that previously had investigated individuals' prototypical conceptions of a moral person (Hardy, Walker, Olsen, Skalski, \& Basinger, 2011; Lapsley \& Lasky, 2001; Smith, Türk Smith, \& Christopher, 2007; 
Walker \& Pitts, 1998). Three of these studies were conduced in the US and Canada, whereas one study used a cross-cultural sample from seven different countries located in Asia, North- and South-America as well as Europe. All studies had employed a free listing method where individuals had been asked to freely generate attributes to describe a moral or a good person. In all four studies, these lists were further distilled by collapsing redundant words or phrases and by eliminating highly idiosyncratic responses. In the study conducted by Walker and Pitts (1998), this procedure yielded 92 descriptors of "a highly moral person", Lapsley and Lasky (2001) identified 170 descriptors, whereas Hardy et al. (2011) reported 94 descriptors. Smith et al. (2007) identified 64 attributes participants from various cultures had generated to describe "a good person". For compiling the list of values as used in the present study, all those descriptors were selected that were listed in at least two out of the four studies. This effectively excluded findings that had not been replicated at least once in an independent study. This procedure resulted in a list of 80 attributes for describing a moral person that covered a broad range of value-orientations from being dependable (e.g., sincere, honest, reliable) and caring (e.g., generous, helpful, selfless) to concerns for fairness and tolerance (e.g., being accepting, open-minded, fair) and conformity (e.g., law abiding) (for a full list of all value-attributes as used in the study, see Table 2). Please note that in pilot interviews, participants were encouraged to add whatever value-attribute they felt was missing on the list. Only one participant out of 20 added one descriptor that was not included in the list ("forward thinking"). Thus, the list of value-attributes as used in the present interview covered individuals' descriptions of a moral person fairly well. 
In the main study, participants were first asked to rate all 80 value-attributes according to how well they describe a highly moral person using a 5-point scale from $1=$ not at all to $5=$ extremely well. Participants were then asked to select those 12 to 15 value-attributes that according to their own personal view, define "the core of a highly moral person". The number of value-attributes (12 to 15) was determined in pilot interviews, as it was found that participants were most comfortable with a set of attributes of this size. The remainder of the interview was based on those 12 to 15 value-attributes individuals had selected for themselves to define a highly moral person. In the sample, the average number of chosen value-attributes was $14.15, S D=1.09$. Participant age was unrelated to the number of attributes chosen, $r(250)=.09, p=0.27$.

To assess the self-importance of moral values, participants were asked to create pictorial self-portraits similar to the method developed by Harter and Monsour (1992) when assessing context-specificities in individuals' self-concept. Participants were given a set of magnetic labels with the chosen value-attributes and a diagram that displayed three nested circles representing varying levels of self-importance. Participants were instructed to place each label in the circle that signified its level of importance to the self (from not important at the outer periphery to very important at the center of the diagram, for an illustration see Figure 1). There were three diagrams with different headings, one representing the social context of family ("How important is it for you to be in the context of your family?"), work or school (depending on enrollment status) ("How important is it for you to be ___ in the context of work/school?") and community/the larger society ("How important is it for you to be ___ in the context of your community and the larger society?"). Participants worked on the three diagrams consecutively. 
Ordering of the diagrams was randomized. Based on this procedure various statistical indices were calculated. These indices reflect (a) the self-importance of moral values (mean-level across social contexts), (b) cross-context differentiation of moral identity, and (c) the relative importance of different value domains for defining a person's moral identity.

Mean-level of moral identity. In order to assess mean-level of individuals' moral identity regardless of context specificity and regardless of value domain, self-importance ratings of the selected 12 to 15 value-attributes $(1=$ not important to me to $4=$ very important to me) were averaged across social contexts and then combined into a single scale. Internal consistency for this scale was $\alpha=.84$. Sample mean was $3.29, S D=0.31$.

\section{Cross-context differentiation of moral identity. Cross-context differentiation of} moral identity was assessed by calculating standard-deviations across social contexts for each value-attribute chosen by the participant (for a discussion of various indices representing intraindividual variation in personality, see Baird, Le, \& Lucas, 2006). The internal consistency of this sum score was $\alpha=.81$. Since variability scores and means tend to be positively correlated when variables are skewed (Baird et al., 2006), standardized residuals were computed by regressing cross-context differentiation on mean-level of moral identity using standard linear regression techniques. This score reflects cross-context differentiation in moral identity independently of mean-level. (The independence of mean-level and cross-context differentiation is further illustrated in Figure 1. It presents two hypothetical interview protocols with equal mean-levels in moral identity but low versus high scores in cross-context differentiation). 
Value domains defining moral identity. In order to assess what values define a person's moral identity, Schwartz's circumplex model was employed as an analytical tool. Schwartz's model has been validated in several independent studies with large crosscultural data sets (Schwartz, 1992; Schwartz et al., 2012). In its original version, the model identifies ten domains that constitute the basic structure of human values (universalism, benevolence, conformity, tradition, security, power, achievement, stimulation and self-direction). More recently, Schwartz et al. (2012) provided a refined model that further differentiated the original ten into 19 value domains. Note, however, that the differentiated model does not invalidate the original ten value domains (cf. Schwartz et al., 2012).

Based on the theoretical descriptions of the value domains, as well as items that have been used in the past to assess these value domains, all 80 value-attributes used in the present study were classified into value domains. We used the more differentiated 19 values domain model whenever possible. However, if a particular value differentiation was not reflected in the list of 80 value-attributes, the original model was applied (this was the case for the distinction between self-direction thought and self-direction action). If a value-attribute was deemed too ambiguous for classification, it was considered unscorable.

All 80 value-attributes were classified by five independent coders (senior researcher and graduate students) who had familiarized themselves with Schwartz's circumplex model. Intercoder agreement ranged from $\kappa=.82$ to .90 with a median score of .85. All discrepancies in codings were discussed and could be unanimously resolved. This process yielded 12 value domains that made up the list of 80 value-attributes as used 
in the present study (for a full list of all value-attributes and their categorization see Table 2): benevolence-dependability (10 attributes out of 80$)$, benevolence-caring (10 attributes), universalism-tolerance (10 attributes), universalism-concern (3), self-direction (7), conformity-rules (4), conformity-interpersonal (7), achievement (6), face (3), tradition (4), hedonism (3), and security-personal (2). Twelve value-attributes (out of 80) were not classified.

The value domains participants chose reflect their concept of a highly moral person but not necessarily their own moral identity. To assess different value-orientations in individuals' moral identity, it was counted how often participants chose a particular value domain as very important to the self in the three social contexts family, school/work, or community. These tallies were divided by the overall number of attributes that were considered as very important across all three contexts by the participant $(M=19.75, S D=8.29)$ and multiplied by 100 , yielding a percentage score of the relative importance of each value domain for defining a person's moral identity. On average, $29.6 \%$ of value-attributes that were considered very important to the self belonged to the domain of benevolence-dependability (e.g., genuine, honest, reliable), followed by universalism-tolerance with $17.82 \%$ (e.g., accepting, non-judgmental, understanding) and benevolence-caring with $10.94 \%$ (e.g., generous, helpful, kind). Universalism-concern, self-direction, conformity-rules and conformity-interpersonal each represented approximately $5 \%$ of individuals' moral identity choices, whereas the percentages of all other value domains were lower (see Table 2). Even though benevolence and universalism clearly were the most important value domains that define individuals' moral identity, together these domains accounted only for $64 \%$ of identity 
choices. Thus, individuals' moral identities involved a broader range of value-orientations than covered by standard measures of moral identity.

Personality traits. For the assessment of personality traits the NEO-FFI-3 inventory was used (McCrae \& Costa, 2004). The NEO-FFI-3 is a 60-item questionnaire for the measurement of the Big Five-personality traits of openness to experience, extraversion, agreeableness, conscientiousness, and neuroticism. Openness to experience refers to the individuals' imagination, curiosity, and intellectual independence. Extraversion involves seeking social stimulation and affiliation. Agreeableness describes individuals' cooperativeness, altruism and empathy. Conscientiousness describes individuals' self-organization and self-discipline. Finally, neuroticism reflects the degree to which individuals experience negative affect such as sadness and anger. In the NEOFFI-3, each personality trait is represented by 12 items, which are rated on a 5-point scale. In the present study, internal consistencies for the five dimensions ranged from $\alpha=$ .74 (openness) to .86 (conscientiousness), with .84 (neuroticism), .81 (agreeableness), .79 (extraversion) in between. Sample means and $S D$ s were $M=3.71, S D=0.52$, for agreeableness, $M=3.68, S D=0.56$, for conscientiousness, $M=3.55, S D=0.51$ for openness to experience, $M=3.47, S D=0.51$, for extraversion and $M=2.89, S D=0.62$, for neuroticism.

Social desirability. Social desirability response bias was measured using a wellvalidated questionnaire originally developed by Stöber (2001) and translated into English by Blake, Valdiserri, Neuendorf, and Nemeth (2006). Participants were presented with 17 statements describing socially desirable or undesirable behaviors (e.g. "I always eat a healthy diet") and were asked to indicate if the statement described them, using a 
dichotomous 1 = true vs. 2 =false-response format. After reverse scoring the negative items, an average score was calculated, $M=1.57, S D=0.20$.

\section{Results}

Investigating the hypotheses as outlined in the introduction involved the examination of empirical relationships between chronological age and (a) mean-level of moral identity across social contexts, (b) cross-context differentiation, and (c) the relative importance of value domains that define a person's moral identity, while controlling for personality traits and other potential confounds (e.g., gender and socio-economic status). We addressed topics (a) to (c) in three separate sets of analyses, each set following the same analytical steps. First, bivariate relationship between age and the relevant variable(s) were examined. This examination included an investigation of quadratic and cubic age-related trends for variables that were expected to evidence non-linear relationships with age. Second, for those moral identity variables that turned out to be significantly related to age, personality traits and other potentially confounding variables were included as predictors in order to investigate to what extent these factors account for age-related trends in moral identity. In a set of preliminary analyses, we identified relevant personality traits and other controls to be included in the main analyses.

\section{Preliminary Analyses}

Personality traits and age. In the present sample, conscientiousness and agreeableness were both found to be positively correlated with age (in years), $r \mathrm{~s}(250)=$ $.24, p<.01$, and $.13, p=.03$ respectively, whereas neuroticism was negatively correlated with age, $r(250)=-.37, p<.01$. By contrast, openness to experience and extraversion did not evidence any linear age-related trend, $r \mathrm{~s}(250)=.05, p=.39$, and $-.04, p=.55$, 
respectively. These findings ertr consistent with previous research on personality trait development in adulthood.

Personality traits and moral identity. Consistent with the notion that conscientiousness, agreeableness and neuroticism define important moral personality traits, mean-level of moral identity (averaged across social contexts) was positively correlated with conscientiousness and agreeableness, $r \mathrm{~s}(250)=.29$ and .30 , respectively, $p s<.01$, and negatively correlated with neuroticism, $r(250)=-.26, p<.01$. Openness to experience and extraversion were not significantly correlated with mean-level of moral identity, $r \mathrm{~s}(250)=-.01, p=.88$, and $.11, p=.08$, respectively. In a multiple regression, all three personality traits significantly contributed to the prediction of mean-level of moral identity, agreeableness, $\beta=.21, p<.01$, conscientiousness, $\beta=.17, p<.01$, neuroticism, $\beta=-.14, p=.04$. The effects of openness and extraversion, by contrast, were not significant.

Cross-context differentiation of moral identity (standardized residuals, controlled for mean-level) was positively correlated with openness, $r(250)=.14, p=.03$, but not with any other personality trait. A multiple regression of cross-context differentiation of moral identity on personality traits did not yield a significant result, $F(5,246)=2.07, p=$ .07 .

As a result of these preliminary analyses, conscientiousness, agreeableness and neuroticism were included as personality traits in the main analyses. These personality traits may (at least partly) account for the relationships between measures of individuals' moral identity and age. 
Gender, SES, social desirability and moral identity. A multiple regression with mean-level of moral identity as dependent variable and gender, SES, and social desirability response bias as predictors, yielded a significant overall effect, $F(3,248)=$ $5.70, p<.01$. Social desirability response bias was a significant predictor of individuals' moral identity mean-level, $\beta=.24, p<.01$. However, gender and SES were not significantly related to mean-level of moral identity, $\beta=.08, p=.19$ and $.004, p=.99$, respectively.

A multiple regression of cross-context differentiation of moral identity on gender, SES and social desirability did not yield a significant overall effect, $F(3,248)=0.22, p=$ .88. None of the regression coefficients of the individual predictors reached the level of statistical significance.

As a result of these preliminary analyses, social desirability response bias was used as a control variable in the main analyses, whereas gender and SES were not.

\section{Main Analyses}

Mean-level of moral identity and age. The bivariate correlation between meanlevel of moral identity (averaged across contexts) and age was $r(250)=.22, p<.01$. Investigating linear and non-linear effects by regressing mean-level of moral identity on age as well as the square root and cubic root of age yielded a significant linear effect $F(1$, $250)=13.05, p<.01, \beta=.23$, whereas non-linear effects did not explain additional variance.

The linear effect of age on mean-level of moral identity was further investigated by entering personality traits and social desirability in a multiple regression together with age (see Table 3). Personality traits significantly predicted mean-level of moral identity 
above and beyond age, $\Delta F(4,246)=8.16, p<.01$. Agreeableness positively predicted mean-level of moral identity, whereas conscientiousness and neuroticism did not uniquely contribute to the regression. When controlling for personality traits, the effect of age was somewhat reduced but still significant (see Table 3). The effect of social desirability was not significant.

Cross-context differentiation of moral identity and age. The bivariate correlation between cross-context differentiation of moral identity (standardized residual score, controlled for mean-level) and age was $r(250)=-.13, p=.04$. The linear effect of age was significant, $F(1,250)=4.25, p=.04$, as was the quadratic effect (square root of age), $\Delta F(1,249)=3.95, p=.04$.

The regression coefficient for the linear effect of age was negative indicating an overall decrease in context-differentiation with age (see Table 3). At the same time, however, the positive quadratic (square root) effect of age demonstrated that crosscontext differentiation tended to increase in younger age groups. The joint function of linear and quadratic effects is displayed in Figure 2, which demonstrates that crosscontext differentiation in moral identity increased between the age of 14 to 25 years and declined afterwards.

When entering personality traits and social desirability response bias in the regression the amount of variance explained did not significantly increase, $\Delta F(4,245)=$ $0.39, p=.80$. Thus, the relationship between cross-context differentiation and age was independent of agreeableness, conscientiousness, neuroticism and social desirability. The linear effect of age remained significant, whereas the quadratic effect was slightly reduced. 
Value domains defining moral identity and age. Bivariate correlations between chronological age and the relative importance of value domains for defining a person's moral identity are summarized in Table 2. Dependability, self-direction and ruleconformity tended to be positively correlated with age, whereas universalism-tolerance as well as achievement evidenced a negative correlation $(p s<.05)$. Thus, value-attributes such as being reliable, responsible, having integrity, being consistent, ethical and lawabiding were more important for older people in the present sample. In contrast, being open-minded, understanding, hard-working and proud tended to be more important for younger age-groups.

These effects of age were further investigated by controlling for personality traits of conscientiousness, agreeableness and neuroticism as well as social desirability response bias in a series of regression analyses. Findings of these regressions are summarized in Table 4. For the value domain of dependability, including personality traits did not yield a significant increase in the variance explained, $\Delta F(4,241)=1.73, p=$ .142. At the same time, once personality traits were statistically controlled the effect of age turned out to be non-significant (see Table 4). Thus, age-related differences in the importance of dependability were largely attributable to age-related differences in personality traits. Similar findings were obtained for universalism-tolerance and achievement.

Including personality traits and social desirability in the regression of universalism-tolerance yielded a significant increase in explained variance with $\Delta F(4$, $241)=6.57, p<.01$. Universalism-tolerance was positively predicted by agreeableness and inversely related to conscientiousness. However, once personality traits were 
statistically controlled the effect of age was not significant. For the value domain of achievement, including personality measures yielded a significant incremental effect, $\Delta F(4,241)=3.01, p<.05$. The importance of the achievement domain was inversely related to agreeableness. Again, effects of age turned out to be non-significant once personality traits were statistically controlled (see Table 4).

For the value domains of self-direction and rule-conformity a different pattern of findings emerged. Including personality traits yielded a significant increase in the predictive effect for both value domains, $\Delta F(4,241)=3.46, p<.01$ for self-direction and $\Delta F(4,241)=2.57, p<.05$ for rule-conformity. The importance of both value domains was positively correlated with age, even when personality traits of agreeableness, conscientiousness and neuroticism were statistically controlled. Agreeableness inversely predicted the importance self-direction, whereas conscientiousness and neuroticism did not significantly contribute to the regression (see Table 4). By contrast, rule-conformity was positively predicted by conscientiousness. Thus, individuals who scored high on conscientiousness valued rule-conformity more as an important aspect of their moral identity. Social desirability response bias did not contribute to the prediction any value domain.

\section{Discussion}

The present study investigated age-related differences in moral identity across adulthood, which has been a largely uncharted area of research up to date. It was argued that a life span approach to the moral identity construct involves more than just extending the age range of previous studies but requires expansions in the conceptualization and measurement of the moral identity construct itself. In the present study, moral identity 
was conceptualized as a context-dependent self-structure that becomes differentiated and (re)integrated in the course of development and that entails a broad range of valueorientations. Based on this conceptualization, we introduced a modified version of the Good Self Assessment, which included a context specific assessment and an expanded range of value-orientations for defining one's moral identity.

Consistent with the notion that personality development trends towards maturity (Roberts et al., 2008), a positive correlation between individuals' mean-level of moral identity and age (14 to 65 years) was found. As individuals grow older, they assign greater self-importance to those values they consider essential for defining a highly moral person. This effect of age only partially overlapped with age-related changes in personality traits. Age was a significant predictor of mean-level of moral identity even when agreeableness, conscientiousness and neuroticism were statistically controlled. In the present sample covering an age range from 14 to 65 years, age-related increases in moral identity were found to be linear, whereas changes in personality traits agreeableness, conscientiousness and neuroticism generally tend to peak between the ages of 20 and 45 years (Roberts, Walton, \& Viechtbauer, 2006). Thus, age-related differences in moral identity and personality did not simply mirror each other. This may suggest that moral identity and personality are complementary in fostering greater maturity over the life span (cf. Hill \& Roberts, 2010).

Because of the conceptual orientation of previous moral identity research towards either trait-based or socio-cognitive approaches, context-specificity of moral identity along with processes of differentiation and integration have been largely neglected up to date. Differentiation and integration define general principles of development (Raeff, 
2011) and important characteristics self-development (Harter, 2012). The present study provided evidence that these principles apply to moral identity development, as well. When assessing moral identity separately in the contexts of family, work or school and community/society, it was found that cross-context differentiation in moral identity increased between adolescence and emerging adulthood and was lower in older agegroups. This trend was independent of personality traits. The finding suggests that during adolescence and emerging adulthood individuals become more aware of changing moral priorities under varying circumstances. This process of differentiation is followed by the tendency to (re)integrate value priorities so that moral identities are not only defined by the self-importance of particular values, but by their consistent importance across different areas of life. This consistency may bolster individuals' sense of agency, as moral actions may be experienced as emanating from the self rather than from demand characteristics of external circumstances. Thus, the decline in cross-context differentiation in moral identities in adulthood may indicate that agentic desires become better integrated with morality, which has been described as an important goal of moral identity development by Frimer and Walker (2009).

Along with age-related changes in mean-level and cross-context differentiation, the moral values that define a person's moral identity shift. In the present study, benevolence, self-direction and rule-conformity tended to be more important for older participants when defining their moral identity as compared to younger participants. By contrast, tolerance and achievement was negatively correlated with age. Again, these effects partly overlapped with age-related differences in personality traits. Effects of age disappeared for benevolence, tolerance and achievement once personality traits were 
statistically controlled. In contrast, self-direction and rule-conformity were significantly related to age even when controlling for agreeableness, conscientiousness and neuroticism. At this point, it remains an open question whether these findings reflect effects of development, cohort, or both.

The relationships between value-orientations and age as obtained in the present study largely correspond with findings reported by Schwartz et al. (2012) and Robinson (2013), with one exception. Whereas a weak negative correlation between the importance of self-direction and age was found in previous studies, in the present study this correlation was positive. When the focus is on moral identity (rather than valueorientations in general), the meaning of self-direction may shift from being free and independent towards maintaining one's integrity. It has been repeatedly demonstrated that individuals' life-goals become increasingly intrinsic with age as they become better aligned with basic psychological needs of autonomy, competence and relatedness (Ryan \& Deci, 2008; Sheldon \& Kasser, 2001). Morgan and Robinson (2012) demonstrated that the intrinsicality of life-goals is positively correlated with seeking personal meaning by leading a principled life. From this perspective, values that stress self-direction and autonomy may be more important for older than for younger individuals when defining their moral identity. Moreover, the finding that self-direction becomes more important with age for individuals when defining their moral identity is consistent with Loevinger's notion (Loevinger, 1993) that conscientiousness as a trait does not merely reflect a single personality factor but two different levels of ego development (conformist vs. conscientious). Correspondingly, age-related increases in conscientiousness as a trait may 
result not only in greater desire for conformity, but also in higher importance of selfdirection and moral integrity.

It should be noted at this point that the three value domains that evidenced the strongest associations with age (self-direction, rule-conformity and universalismtolerance) are typically not included in common measures of moral identity such as the Self-Importance of Moral Identity Questionnaire (Aquino \& Reed, 2002) and the Good Self Assessment (Arnold, 1993). As a consequence, these measures likely underestimate age-related change in moral identity.

A major limitation of the study is in its cross-sectional design, which made it impossible to track individual change over time and to disentangle reciprocal effects between development of moral identity and personality traits. Moreover, because of the cross-sectional design, any age-related differences may be confounded with cohort effects. Empirical evidence for developmental effects in moral identity obtained in the present study is therefore only indirect. Secondly, the sample of the present study was not representative and limited to a particular socio-cultural context in a Western society. As a consequence, it is unclear to what extent findings can be generalized to other cultural contexts. Thirdly, the age range of present study was limited to 65 years. This was necessitated by the context specific assessment that included moral identity at the workplace. For many elderly people, morality at the workplace would not be a relevant identity concern. Moreover, some older participants might experience difficulties to engage in a 90-minute assessment of moral identity. Thus, future studies will have to expand the age range while using a slightly modified assessment procedure in order to track moral identity development in old age. 
By conceptualizing moral identity as a context-dependent self-structure that involves a broad range of value-orientations, the present study documented age-related differences in individuals' moral identity that are consistent with important developmental principles and with well-established longitudinal findings in the area of adult personality development. This confirms the developmental nature of the moral identity construct. Moral identity development is not restricted to adolescence or emerging adulthood. It is a life-long process that expands well into adulthood. 


\section{References}

Aquino, K., \& Reed, A. (2002). The self-importance of moral identity. Journal of Personality and Social Psychology, 83, 1423-1440.

Baird, B. M., Le, K., \& Lucas, R. E. (2006). On the nature of intraindividual personality variability: reliability, validity, and associations with well-being. Journal of Personality and Social Psychology, 90(3), 512-527. http://doi.org/10.1037/00223514.90 .3 .512

Barriga, A. Q., Morrison, E. M., Liau, A. K., \& Gibbs, J. C. (2001). Moral Cognition: Explaining the Gender Difference in Antisocial Behavior. Merrill-Palmer Quarterly. http://doi.org/10.1353/mpq.2001.0020

Blake, B. F., Valdiserri, J., Neuendorf, K. A., \& Nemeth, J. (2006). Validity of the SDS17 measure of social desirability in the American context. Personality and Individual Differences, 40(8), 1625-1636. http://doi.org/10.1016/j.paid.2005.12.007

Blasi, A. (2005). Moral character: A psychological approach. In D. K. Lapsley \& F. C. Power (Eds.), Character psychology and character education (pp. 67-100). Notre Dame: University of Notre Dame Press.

Bleidorn, W., Klimstra, T. a., Denissen, J. J. a., Rentfrow, P. J., Potter, J., \& Gosling, S. D. (2013). Personality Maturation Around the World: A Cross-Cultural Examination of Social-Investment Theory. Psychological Science, 24(12), 2530-2540. http://doi.org/10.1177/0956797613498396

Brenick, A., \& Killen, M. (2014). Moral judgments about Jewish-Arab intergroup exclusion: the role of cultural identity and contact. Developmental Psychology, 50(1), 86-99. http://doi.org/10.1037/a0034702 
Damon, W., \& Hart, D. (1988). Self-understanding in childhood and adolescence. New York: Cambridge University Press.

Diehl, M., Hastings, C. T., \& Stanton, J. M. (2001). Self-concept differentiation across the adult life span. Psychology and Aging, 16(4), 643-654. http://doi.org/10.1037/0882-7974.16.4.643

Diehl, M., \& Hay, E. L. (2007). Contextualized self-representations in adulthood. Journal of Personality, 75(6), 1255-83. http://doi.org/10.1111/j.1467-6494.2007.00475.x

Diehl, M., \& Hay, E. L. (2011). Self-concept differentiation and self-concept clarity across adulthood: Associations with age and psychological well-being. The International Journal of Aging and Human Development, 73(2), 125-152. http://doi.org/10.2190/AG.73.2.b

Donahue, E. M., Robins, R. W., Roberts, B. W., \& John, O. P. (1993). The divided self: Concurrent and longitudinal effects of psychological adjustment and social roles on self-concept differentiation. Journal of Personality and Social Psychology, 64(5), 834-846. http://doi.org/10.1037//0022-3514.64.5.834

Elbogen, E. B., Carlo, G., \& Spaulding, W. (2001). Hierarchical classification and the integration of self-structure in late adolescence. Journal of Adolescence, 24(5), 657670. http://doi.org/10.1006/jado.2001.0421

Flanagan, O. (1991). Varieties of moral personality. Ethics and psychological realism. Cambridge: Harvard University Press.

Frimer, J. A., \& Walker, L. J. (2009). Reconciling the self and morality: An empirical model of moral centrality development. Developmental Psychology, 45, 1669-1681. 
Ganzeboom, H. B. G., De Graaf, P. M., \& Treiman, D. J. (1992). A standard international socio-economic index of occupational status. Social Science Research, 21(1), 1-56. http://doi.org/10.1016/0049-089X(92)90017-B

Goodwin, G. P., Piazza, J., \& Rozin, P. (2014). Moral character predominates in person perception and evaluation. Journal of Personality and Social Psychology, 106(1), 148-68. http://doi.org/10.1037/a0034726

Graham, J., Haidt, J., Koleva, S., Motyl, M., Iyer, R., Wojcik, S. P., \& Ditto, P. H. (2013). Moral Foundations Theory: The Pragmatic Validity of Moral Pluralism. Advances in Experimental Social Psychology, 47, 55-130. http://doi.org/10.1016/B978-0-12-407236-7.00002-4

Graham, J., Nosek, B. A., Haidt, J., Iyer, R., Koleva, S., \& Ditto, P. H. (2011). Mapping the moral domain. Journal of Personality and Social Psychology, 101(2), 366-385. http://doi.org/10.1097/00005053-199107000-00016

Hardy, S., \& Carlo, G. (2011a). Moral identity. In S. J. Schwartz (Ed.), Handbook of identity theory and research (pp. 495-513). New York: Springer Science+Business Media.

Hardy, S., \& Carlo, G. (2011b). Moral Identity: What is it, how does it develop, and is it linked to moral action? Child Development Perspectives, 5, 212-218.

Hardy, S., Walker, L. J., Olsen, J. A., Skalski, J. E., \& Basinger, J. C. (2011). Adolescent naturalistic conceptions of moral maturity. Social Development, 20(3), 562-586. http://doi.org/10.1111/j.1467-9507.2010.00590.x

Harter, S. (2012). The construction of the self: A developmental perspective. New York: Guilford Press. 
Harter, S., Bresnick, S., Bouchey, H. A., \& Whitesell, N. R. (1997). The development of multiple role-related selves during adolescence. Development and Psychopathology, 9(4), 835-853. http://doi.org/10.1017/S0954579497001466

Harter, S., \& Monsour, A. (1992). Developmental analysis of conflict caused by opposing self-attributes in the adolescent self-portrait. Developmental Psychology, 28, 251260.

Hill, P. L., \& Roberts, B. W. (2010). Propositions for the study of moral personality development. Current Directions in Psychological Science, 19(6), 380-383. http://doi.org/10.1177/0963721410389168

Horn, S. S. (2003). Adolescents' reasoning about exclusion from social groups. Developmental Psychologysychology, 39(1), 71-84. http://doi.org/10.1037/00121649.39 .1 .71

Johnston, M., \& Krettenauer, T. (2011). Moral self and moral emotion expectancies as predictors of anti- and prosocial behaviour in adolescence: A case for mediation? European Journal of Developmental Psychology, 8(2), 228-243. http://doi.org/10.1080/17405621003619945

Kochanska, G. (2002). Committed compliance, moral self, and internalization: A mediational model. Developmental Psychology, 38, 339-351.

Kochanska, G., Koenig, J. L., Barry, R. A., Sanghang, K., \& Yoon, J. E. (2010). Children's conscience during toddler and preschool years, moral self, and a competent, adaptive developmental trajectory. Developmental Psychology, 46, $1320-1332$. 
Krettenauer, T., Asendorpf, J. B., \& Nunner-Winkler, G. (2013). Moral emotion attributions and personality traits as long-term predictors of antisocial conduct in early adulthood: Findings from a 20-year longitudinal study. International Journal of Behavioral Development, 37(3), 192-201. http://doi.org/10.1177/0165025412472409

Krettenauer, T., Campbell, S., \& Hertz, S. (2013). Moral emotions and the development of the moral self in childhood. European Journal of Developmental Psychology, 10(2), 159-173. http://doi.org/10.1080/17405629.2012.762750

Krettenauer, T., Colasante, T., Buchmann, M., \& Malti, T. (2014). The Development of Moral Emotions and Decision-Making From Adolescence to Early Adulthood: A 6Year Longitudinal Study. Journal of Youth and Adolescence, 43(4), 583-596. http://doi.org/10.1007/s10964-013-9994-5

Lapsley, D. K., \& Hill, P. L. (2009). The development of moral personality. In D. Narvaez \& D. K. Lapsley (Eds.), Personality, identity, and character (pp. 185-213). Cambridge: Cambridge University Press.

Lapsley, D. K., \& Lasky, B. (2001). Prototypic moral Character. Identity, 1(4), 345-363. http://doi.org/10.1207/S1532706XID0104_03

Lapsley, D. K., \& Narvaez, D. (2004). A social-cognitive approach to the moral personality. In D. K. Lapsley \& D. Narvaez (Eds.), Moral development, self, and identity (pp. 189-212). Mahwah, NJ: Erlbaum.

Lapsley, D. K., \& Stey, P. C. (2014). Moral self-identity as the aim of education. In L. Nucci, D. Narvaez, \& T. Krettenauer (Eds.), Handbook of Moral and Character Education (pp. 84-100). New York: Routledge. 
Loevinger, J. (1993). Conformity and conscientiousness: One factor or two stages? In D. C. Funder, R. D. Parke, C. Tomlinson-Keasy, \& K. Widaman (Eds.), Studying lives through time (pp. 189-205). Washington, DC: American Psychological Association.

Lucas, R. E., \& Donnellan, M. B. (2011). Personality development across the life span: Longitudinal analyses with a national sample from Germany. Journal of Personality and Social Psychology, 101(4), 847-861. http://doi.org/10.1037/a0024298

McAdams, D. P. (2009). The moral personality. In D. Narvaez \& D. K. Lapsley (Eds.), Personality, identity, and character: Explorations in moral psychology. (pp. 11-29). Cambridge: Cambridge University Press. http://doi.org/10.1017/CBO9780511627125.002

McAdams, D. P. (2015). Tracing Three Lines of Personality Development. European Psychologist, 20(4), 252-264. http://doi.org/10.1080/15427609.2015.1068057

McAdams, D. P., \& Olson, B. D. (2010). Personality development: continuity and change over the life course. Annual Review of Psychology, 61(5), 517-42. http://doi.org/10.1146/annurev.psych.093008.100507

McCrae, R. R., \& Costa, P. T. (2004). A contemplated revision of the NEO Five-Factor Inventory. Personality and Individual Differences, 36(3), 587-596. http://doi.org/10.1016/S0191-8869(03)00118-1

Miller, J. D., \& Lynam, D. (2001). Structural models of personality and their relation to antisocial behavior: A meta-analytic review. Criminology, 39(4), 765-798. http://doi.org/10.1111/j.1745-9125.2001.tb00940.x 
Morgan, J., \& Robinson, O. (2012). Intrinsic aspirations and personal meaning across adulthood: conceptual interrelations and age/sex differences. Developmental Psychology, 49(5), 999-1010. http://doi.org/10.1037/a0029237

Nunner-Winkler, G., Meyer-Nikele, M., \& Wohlrab, D. (2007). Gender Differences in Moral Motivation. Merrill-Palmer Quarterly (Vol. 53).

Raeff, C. (2011). Distinguishing between development and change: Reviving organismicdevelopmental theory. Human Development, 54(1), 4-33. http://doi.org/10.1159/000324334

Roberts, B. W., \& DelVecchio, W. F. (2000). The rank-order consistency of personality traits from childhood to old age: A quantitative review of longitudinal studies, Psychologi(126), 3-25.

Roberts, B. W., Walton, K. E., \& Viechtbauer, W. (2006). Patterns of mean-level change in personality traits across the life course: A meta-analysis of longitudinal studies. Psychological Bulletin, 132, 1-25.

Roberts, B. W., \& Wood, D. (2006). Personality development in the context of the neosocioanalytic model of personality. In D. K. Mroczek \& T. D. Little (Eds.), Handbook of personality development (pp. 11-39). Mahwah, NJ: Erlbaum.

Roberts, B. W., Wood, D., \& Caspi, A. (2008). The develoment of personality traits in adulthood. In P. John, R. W. Robins, \& L. A. Pervin (Eds.), Handbook of personality (pp. 375-398). New York: Guilford.

Roberts, B. W., Wood, D., \& Smith, J. L. (2005). Evaluating Five Factor Theory and social investment perspectives on personality trait development. Journal of Research in Personality, 39, 166-184. http://doi.org/10.1016/j.jrp.2004.08.002 
Robinson, O. (2013). Values and adult age: findings from two cohorts of the European Social Survey. European Journal of Ageing, 10(1), 11-23. http://doi.org/10.1007/s10433-012-0247-3

Roccas, S., Sagiv, L., Schwartz, S. H., \& Knafo, A. (2002). The Big Five Personality Factors and Personal Values. Personality and Social Psychology Bulletin, 28(6), 789-801. http://doi.org/10.1177/0146167202289008

Ryan, R. M., \& Deci, E. L. (2008). Self-Determination Theory and the role of basic psychological needs in personality and the organization of behavior. In P. John, R. W. Robins, \& L. A. Pervin (Eds.), Handbook of personality (pp. 654-678). New York: Guilford.

Schwartz, S. H. (1992). Universals in the content and structure of values: Theoretical advances and empirical tests in 20 countries. In M. Zanna (Ed.), Advances in Experimental Social Psychology (Vol. 25) (pp. 1-65). New York: Academic Press.

Schwartz, S. H. (2006). Basic human values: Theory, measurement, and applications. Revue Française de Sociologie, 47, 249-288.

Schwartz, S. H., Cieciuch, J., Vecchione, M., Davidov, E., Fischer, R., Beierlein, C., ... Konty, M. (2012). Refining the theory of basic individual values. Journal of Personality and Social Psychology, 103(4), 663-88. http://doi.org/10.1037/a0029393

Sengsavang, S., \& Krettenauer, T. (2015). Children's Moral Self-Concept: The Role of Aggression and Parent-Child Relationships. Merrill-Palmer Quarterly, 61(2), 213235. http://doi.org/10.13110/merrpalmquar1982.61.2.0213 
Sheldon, K. M., \& Kasser, T. (2001). Getting older, getting better? Personal strivings and psychological maturity across the life span. Developmental Psychology, 37, 491501.

Smetana, J. G., Jambon, M., \& Ball, C. (2014). The social domain approach to children's moral and social judgments. In M. Killen \& J. G. Smetana (Eds.), Handbook of moral development (pp. 23-45). New York: Psychology Press.

Smith, K. D., Türk Smith, S., \& Christopher, J. C. (2007). What defines the good person? Cross-cultural comparisons of experts' models with lay prototypes, Journal of(2007), 333-360. http://doi.org/10.1177/0022022107300279

Stöber, J. (2001). The Social Desirability Scale-17 (SDS-17). European Journal of Psychological Assessment, 17(3), 222-232. http://doi.org/10.1027//10155759.17.3.222

Vauclair, C.-M., Wilson, M., \& Fischer, R. (2014). Cultural conceptions of morality: Examining laypeople's associations of moral character. Journal of Moral Education, 43(1), 54-74. http://doi.org/10.1080/03057240.2013.873365

Walker, L. J. (2014). Moral personality, motivation, and identity. In M. Killen \& J. G. Smetana (Eds.), Handbook of moral development (pp. 497-519). New York: Psychology Press.

Walker, L. J., \& Pitts, R. C. (1998). Naturalistic conceptions of moral maturity. Developmental Psychology, 34, 403-419.

Wood, D., \& Roberts, B. W. (2006). Cross-sectional and longitudinal tests of the personality and role identity structural model (PRISM). Journal of Personality, 74(3), 779-809. http://doi.org/10.1111/j.1467-6494.2006.00392.x 
Table 1.

Demographic Characteristics of Sample Across Age Groups

\begin{tabular}{lccccc}
\hline & $\begin{array}{c}\text { Adolescent } \\
(14-18 \text { years })\end{array}$ & $\begin{array}{c}\text { Emerging Adulthood } \\
(19-25 \text { years })\end{array}$ & $\begin{array}{c}\text { Young Adulthood } \\
(26-45 \text { years })\end{array}$ & $\begin{array}{c}\text { Middle Age } \\
(46-65 \text { years })\end{array}$ & Full Sample \\
\hline $\mathrm{N}$ & 67 & 52 & 66 & 67 & 252 \\
Female (\%) & $41(61.4)$ & $29(55.8)$ & $43(65.2)$ & $35(52.2)$ & $148(58.7)$ \\
Age in years (SD) & $16.41(1.62)$ & $22.09(2.37)$ & $32.81(5.57)$ & $58.70(7.07)$ & $33.08(17.18)$ \\
$\begin{array}{l}\text { Country of Origin: } \\
\text { Born in Canada (\%) }\end{array}$ & $53(80.3)$ & $39(76.5)$ & $42(64.6)$ & $54(80.6)$ & $188(75.5)$ \\
$\begin{array}{l}\text { Ethnic background: } \\
\text { European-Canadian }(\%)^{\mathrm{a}}\end{array}$ & $51(75.6)$ & $34(65.0)$ & $53(78.9)$ & $56(83.5)$ & $193(76.1)$ \\
Education attainment & N/A & $5.20(1.81)$ & $4.97(1.75)$ & $4.88(1.84)$ & $4.86(1.70)$ \\
SES & $50.21(12.50)$ & $50.81(15.81)$ & $49.20(15.79)$ & $51.75(15.21)$ & $50.46(14.69)$ \\
\hline
\end{tabular}

Note. ${ }^{\text {a }}$ column $\%$ 
Table 2.

Value Domains and Value-Attributes Defining Individuals' Moral Identity, Relative Frequency and Correlations with Age

Value Domain/Attributes

\section{Benevolence-dependability: Being a reliable and trustworthy group member}

- Dependable, faithful, genuine, honest, loyal, reliable, responsible, sincere, trustworthy, truthful

Universalism-tolerance: Acceptance of those who are different from oneself

- Accepting, empathic, listens, non-judgmental, open-minded, patient, respectful, tolerant, understanding, wise

Benevolence-caring: Devotion to the welfare of ingroup members

- Altruistic, benevolent, caring, forgiving, generous, helpful, kind, loving, selfless, sharing

Self-direction ${ }^{\text {a }}$ Cultivate one's own ideas and determine one's own action

- Confident, consistent, courageous, having integrity, independent, rational, self-assured

Conformity-rules: Compliance with rules, laws and formal obligations

- Ethical, follows the rules, law abiding, obedient

Universalism-concern: Commitment to equality, justice and protection for all

- Compassionate, fair, just

Conformity-interpersonal: Avoidance of upsetting other people

- Considerate, cooperative, courteous, conscientious, friendly, nice, sociable

$M \%(S D) \quad r \quad(p)$

$29.62(18.31) \quad .14(.025)$

$17.83(15.47) \quad-.15 \quad(.020)$

$10.95(11.44) \quad-.12 \quad(.055)$

$7.65 \quad(9.02) \quad .19 \quad(.002)$

$6.00 \quad(8.34) \quad .15 \quad(.017)$

$5.97 \quad(7.99) \quad .08 \quad(.213)$

$5.21 \quad(7.87) \quad-.09 \quad(.141)$ 


\section{Achievement: Success according to social standards}

- Educated, hard-working, intelligent, perseveres, proud, self-disciplined

Face: Maintaining once public image and avoiding humiliation

- Exemplary, honorable, upstanding

\section{Tradition: Respect of the customs and ideas that traditional culture or religion provides}

- Grateful, humble, modest, religious

Hedonism: Pleasure and sensuous gratification

- Cheerful, fun, happy

\section{Security-personal: Safety and stability in one's immediate environment}

- Clean, healthy

\section{Unclassified:}

- Good, has high standards, knowledgeable, knows what is right and wrong, makes the right choices, optimistic, proper, righteous, strong, thrifty, virtuous

Note. Definition of value domains from Schwartz et al. (2012). $M \%=$ average percent of attributes chosen by participants as very important to define moral identity in the context family, work/school and community, $S D=$ standard deviation of percentage score, $r=$ correlation of percentage score with age, $(p)=$ two-tailed significance level of correlation based on full sample $(\mathrm{N}=252)$.

${ }^{a}$ Value domain as originally proposed by Schwartz (1992). The differentiation between self-direction-thought and self-direction-action as proposed by Schwartz et al. (2012) was not applicable in the context of the present study. 
Table 3

Results of Regression Analyses Predicting Mean-level and Cross-context Differentiation of Moral Identity by Age, Personality Traits and Social Desirability Response Bias

\begin{tabular}{|c|c|c|c|c|c|c|c|c|}
\hline & \multicolumn{4}{|c|}{ Moral Identity: Mean-Level } & \multicolumn{4}{|c|}{$\begin{array}{l}\text { Moral Identity: } \\
\text { Cross-Context Differentiation }\end{array}$} \\
\hline & \multicolumn{2}{|c|}{ Step 1} & \multicolumn{2}{|c|}{ Step 2} & \multicolumn{2}{|c|}{ Step 1} & \multicolumn{2}{|c|}{ Step 2} \\
\hline & $\beta$ & $t$ & $\beta$ & $t$ & $\beta$ & $t$ & $\beta$ & $t$ \\
\hline Age (linear) & .23 & $3.73 * *$ & .13 & $2.13 *$ & -.12 & $-2.37^{*}$ & -.11 & $-2.19 *$ \\
\hline Age (square root) & - & - & - & - & .20 & $1.98^{*}$ & .19 & 1.84 \\
\hline Agreeableness & & & .20 & $3.05 * *$ & & & -.04 & -0.61 \\
\hline Conscientiousness & & & .12 & 1.66 & & & .07 & 0.99 \\
\hline Neuroticism & & & -.08 & -1.16 & & & .05 & 0.69 \\
\hline Social desirability & & & .09 & 1.42 & & & -.02 & -0.31 \\
\hline$\Delta R^{2}$ & & $1 * *$ & & $113^{* *}$ & & $2 *$ & & 06 \\
\hline
\end{tabular}

Note. $N=252 * * p<.01, * p<.05$. 
Table 4

Results of Regression Analyses Predicting Value Domains Defining Moral Identity by Age, Personality Traits and Social Desirability Response Bias

\begin{tabular}{|c|c|c|c|c|c|c|c|c|c|c|}
\hline & \multicolumn{2}{|c|}{ Dependability } & \multicolumn{2}{|c|}{ Self-Direction } & \multicolumn{2}{|c|}{ Rule-Conformity } & \multicolumn{2}{|c|}{$\begin{array}{l}\text { Universalism- } \\
\text { Tolerance }\end{array}$} & \multicolumn{2}{|c|}{ Achievement } \\
\hline & $\beta$ & $t$ & $\beta$ & $t$ & $\beta$ & $t$ & $\beta$ & $t$ & $\beta$ & $t$ \\
\hline Age (linear) & .11 & 1.53 & .17 & $2.63 * *$ & .14 & $2.08^{*}$ & -.10 & -1.67 & -.11 & -1.67 \\
\hline Agreeableness & .08 & 1.21 & -.22 & $-3.35^{* *}$ & -.07 & -0.97 & .23 & $3.45^{* *}$ & -.18 & $-2.71 * *$ \\
\hline Conscientiousness & .10 & 1.39 & -.01 & -0.15 & .18 & $2.45^{*}$ & -.27 & $-.381 * *$ & .14 & 1.91 \\
\hline Neuroticism & -.01 & -0.15 & -.14 & -1.92 & .14 & 1.91 & -.02 & -0.32 & .09 & 1.23 \\
\hline Social desirability & .11 & 1.45 & .00 & 0.02 & .06 & 0.78 & -.07 & -1.02 & .06 & 0.82 \\
\hline$R^{2}$ & \multicolumn{2}{|c|}{$.045^{*}$} & \multicolumn{2}{|c|}{$.088 * *$} & \multicolumn{2}{|c|}{$.057 *$} & \multicolumn{2}{|c|}{$.12 * *$} & \multicolumn{2}{|c|}{$.065 * *$} \\
\hline
\end{tabular}

Note. $N=252 * * p<.01, * p<.05$. 


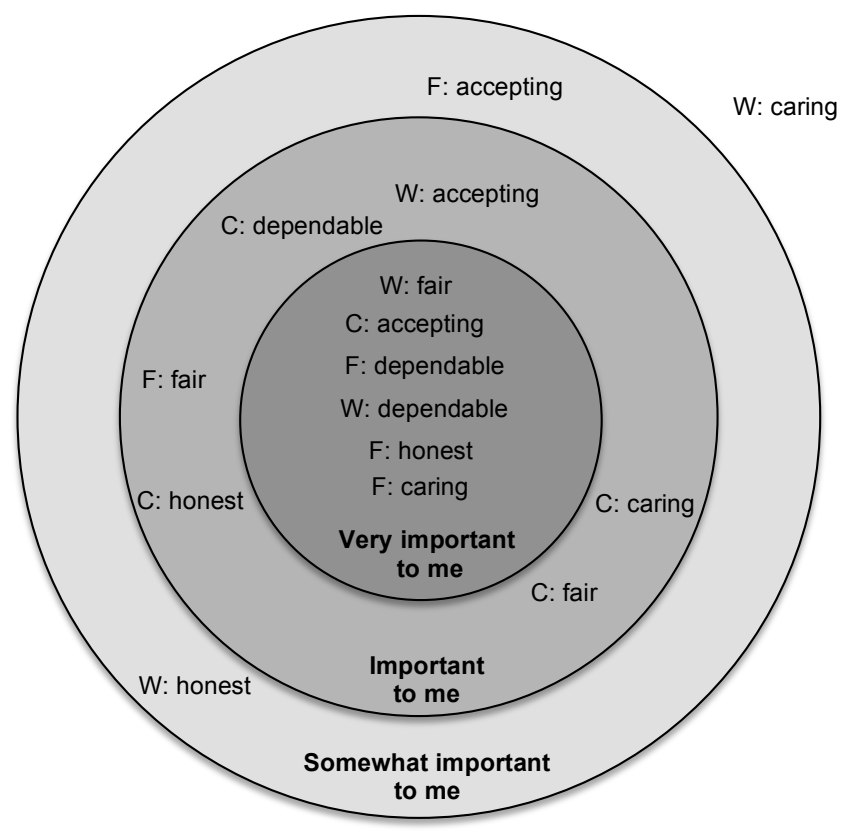

Not important to me

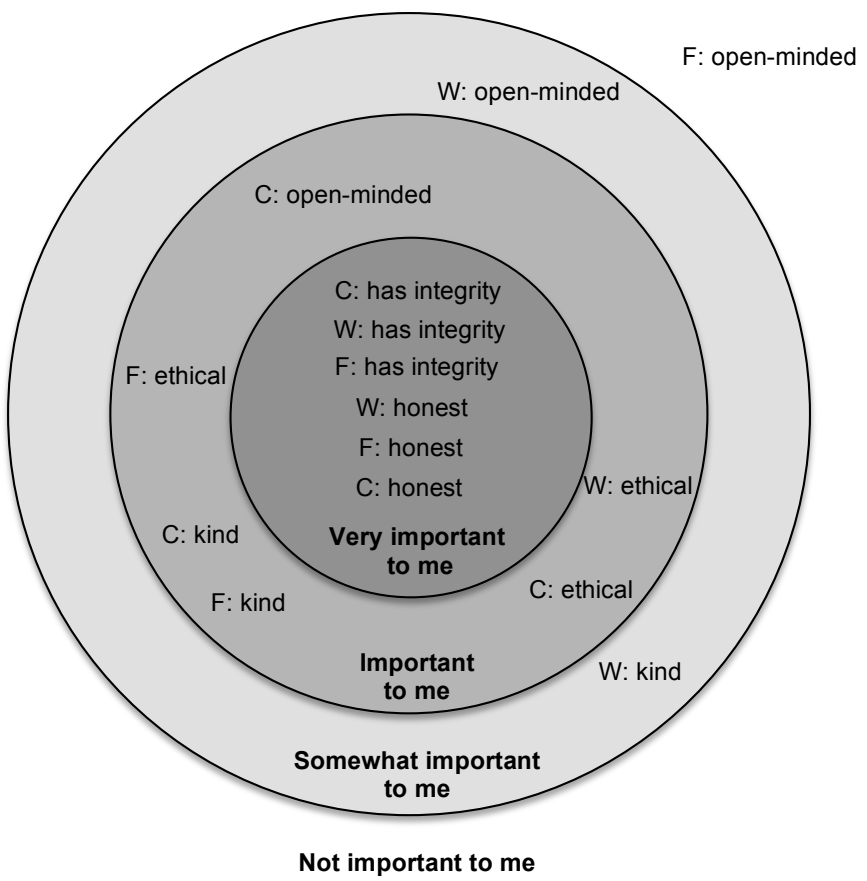

Figure 1

Hypothetical Examples of High (Top) Versus Low (Bottom) Cross-context Differentiation of Moral Identity With Equal Mean-Levels ( $F=$ Family, $W=$ Work, $C=$ Community/Society) 


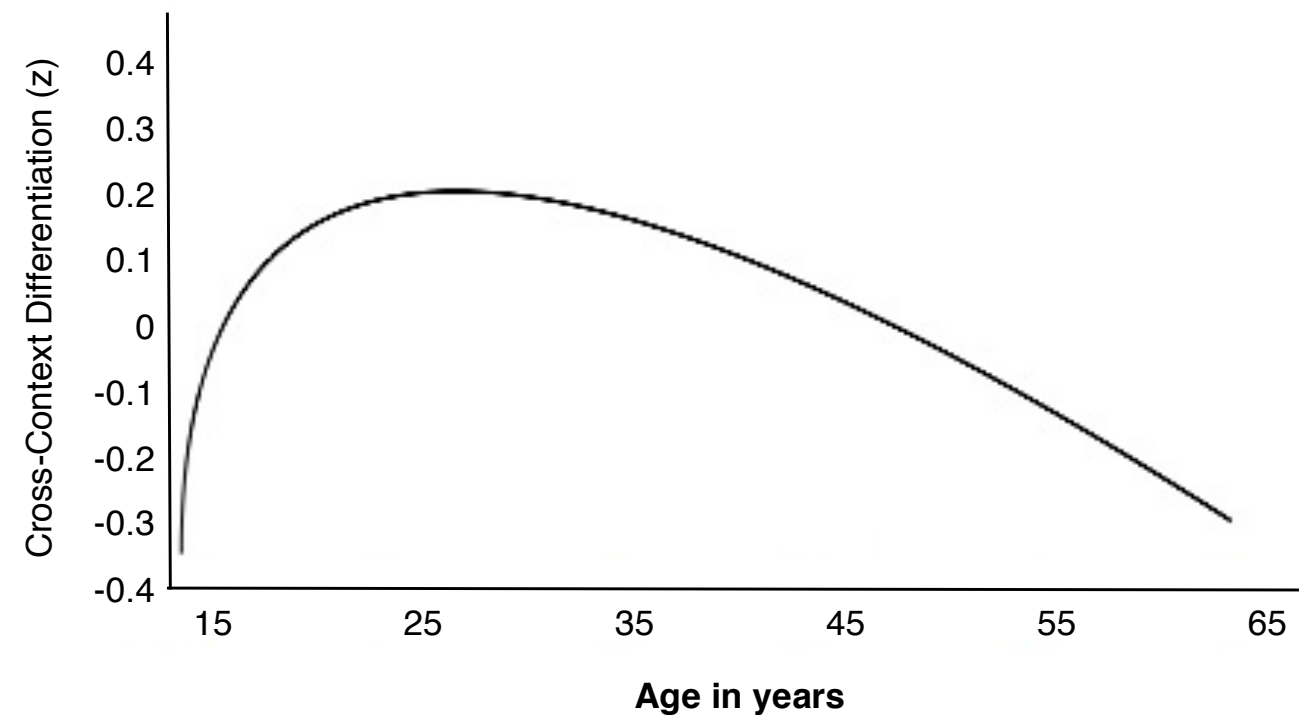

Figure 2

Linear and Non-linear Effects of Age on Cross-context Differentiation of Moral Identity 